\title{
Community-based knowledge towards rangeland condition, climate change, and adaptation strategies: the case of Afar pastoralists
}

\author{
Minyahel Tilahun ${ }^{1}$, Ayana Angassa ${ }^{2,3^{*}}$ and Aster Abebe ${ }^{3}$
}

\begin{abstract}
Introduction: Pastoral communities have a comprehensive knowledge of their environments. This knowledge was acquired through extensive observation of the local environment and continuous herding practices. Pastoralists' wisdom about their local environment and adaptation strategies to climate change is essential for sustainable development. Thus, appreciation of pastoralists' knowledge about their environment is also important for the integration of indigenous knowledge with the proper application of scientific approach to fit with the prevailing ecological potential of pastoral areas.
\end{abstract}

Methods: Data were collected using focus group discussions, key informant interviews, and in-depth interviews. The in-depth interviews were conducted using a semi-structured questionnaire that was administered to 100 household heads with the age of above 50 years old. Respondents were randomly drawn from selected Pastoralists Associations (PAs) of two study districts. Data were analyzed using descriptive statistics as well as the logit model. The logit model was used to analyze the different coping strategies of pastoralists to overcome the failure of rain during different seasons. This was done by complementing pastoralists' indigenous knowledge of time-series-based analysis across four seasons (Kerma, Gillal, Hagay, and Sugum) vs. the existing meteorological records. Forty years (from 1971 to 2011) of existing metrological data were used to compare the empirical evidence with pastoralists' perceptions.

Results: Respondents mentioned that livestock number was the best indicator for evaluating rangeland condition in Afar region. The existing empirical evidence based on metrological data did not show any significant decline in precipitation for the last four decades between 1971 and 2011 as opposed to the perception of pastoralists where $80 \%$ of them reported a decline in precipitation. A one unit increase in labor force suggested about $16.1 \%$ decrease in the choice of livestock selling as coping strategy in Afar pastoral areas of North-East of Ethiopia. The non-intervened pastoral households had more preference (3.78\%) to practice herd splitting than those pastoral households in the intervened district. Similarly, the non-intervened pastoral households had $4.43 \%$ more preference to use crop residue for livestock feeding than pastoral HHs in the intervened areas.

(Continued on next page)

\footnotetext{
*Correspondence: ayana.angassa@gmail.com

${ }^{2}$ Botswana University of Agriculture and Natural Resources, Gaborone,

Botswana

${ }^{3}$ School of Animal and Range Sciences, Hawassa University, Hawassa,

Ethiopia

Full list of author information is available at the end of the article
} 
(Continued from previous page)

Conclusions: Communities' perceptions showed that livestock number was the best indicator of rangeland condition in the study area. Afar pastoralists' observations with regard to temperature and precipitation trends over the last four decades greatly corresponded with the existing metrological-based empirical evidence. However, pastoralists' perception in terms of reduced precipitation was not confirmed by the meteorological-based data records for the short rainy season (SRS). Afar pastoralists' experience showed that the short rainy season was the best indicator for the occurrence of droughts as compared to other seasons in Afar. Our results suggest that most coping strategies are labor force demanding, and the situation worsens during the long rainy season (LRS). We suggest that differences in intervention between the study areas should not be overlooked as a policy tool in tackling the impact of climate change.

Keywords: Climate change, Adaptation, Perception, Precipitation, Temperature, Afar, Rangelands

\section{Introduction}

Since early human beings first moved out of Ethiopia, the world's climate has had a continual impact on the history of human beings. Currently, the climate itself is abused by human civilization. For centuries, the survivals of the fittest are the ones that have been using indigenous knowledge to tackle adverse environmental changes (SFDRR 2015). Ban Ki-moon, the former United Nation's Secretary General, has said, "It is time for global action on resilience and risk reduction that not only anticipate and absorb climate risks, but also reshapes them into an opportunity for safer sustainable development." From this testimony, we can understand that mitigation and adaptation strategies are the key terms to keep the environment resilient. In the past few years, the world society has been working to create a resilient society in addition to introducing appropriate technologies, which make humans life easier. In all means, new science and technological innovations need to reach and engage the different actors beyond the aim of research to enhance its benefits to the concerned members of a society. Thus, proper communication and integration of the results of scientific research with an indigenous knowledge is important to enhance sustainable development among pastoral communities. Pastoral communities usually have a detailed knowledge of the ecology of their grazing lands, acquired through extensive observation and continuous herding practices for centuries (Angassa et al. 2012). The use of indigenous knowledge can provide a basis for developing alternative ways of managing natural resources as coping strategies although such knowledge has been overlooked by policy makers (Mohammed 2010). Despite these challenges, pastoral communities have been surprisingly resilient and have shown a wide variety of adaptations to environmental changes (Carver 1998). Pastoralists have been showing the ability to recover from climate shocks than agropastoralists and non-pastoralists (Shikuku 2017).

In recent years, the pastoral communities seem to become more vulnerable to the impact of drought than they used to be. According to Helland (2006), drought is quite common in the pastoral areas of Ethiopia, which seem to translate into famines more quickly and frequently than in the past. To this end, the first resource in hand is local communities' knowledge, which is important in terms of mitigation and adaptation to the impact of climate change through mobility and seasonal use of grazing lands (Mwenda and Laswai 2013; Li et al. 2014). A theoretical framework which postulates people's perception of climate change is a key process in the formation of mitigation and local adaptive behavior (FosuMensah 2012; Shikuku et al. 2017). This process is an important prerequisite in implementing mitigation and locally adapted strategies to the ongoing environmental changes and rangeland management systems (Tambo and Abdoulaye 2013).

Thus, understanding pastoralists' knowledge about their rangelands and mitigation and adaptation strategies to climate change is essential if they are to be assisted by proper application and adoption of science and technology that is suitable for the ecological potential of arid rangelands. In this paper, the spotlight is community indigenous knowledge about their rangeland and the relationships between pastoralists' perception of climate change and the existing metrological-based empirical data aiming at understanding the perception of pastoralists within differently intervened types of pastoral districts within relatively similar ecological conditions and its correlation with the actual climate change. Several studies with regard to herders' perceptions on climate change issues have been reported in Sudan (Sulieman and Ahmed 2013), Tanzania (Mwenda and Laswai 2013), and other parts of the world (Hou et al. 2012; Li et al. 2014). However, little has been done in evaluating community-based knowledge at a household level about the condition of their rangelands, existing coping strategies adopted by these communities to overcome the impacts of climate change and variability on pastoralists' livelihood as well as spotting the socio-economic factors affecting their coping capacity in Amibara and Gewane districts of Afar region, North-East Ethiopia. Therefore, the objectives of this 
study were (1) to understand pastoralists' perceptions towards rangeland degradation under the impact of climate change; (2) to relate pastoralists' perceptions of climate change to the existing meteorological-based empirical data for the last four decades under different levels of development interventions; and (3) to understand pastoralists' mitigation and adaptation strategies in response to increased pressure from external development interventions and environmental changes.

\section{Theoretical framework}

Climate change has been affecting different production systems throughout the world. However, pastoralism has been the most vulnerable production system (Helland 2015). This is because pastoral production system is situated in harsh, dry, arid, and fragile environments of the world such as in the case of Afar (Mohammed 2010) and Borana (Angassa et al. 2012) pastoral systems of Ethiopia. This situation is coupled up with anthropogenic factors such as improper development intervention (Mohammed 2010; Helland 2015). The Afar region has been known for its frequent drought, which is the major appraised risk for decades. Lots of resolving activities has been tried out to cope up with the recurrent droughts based on their indigenous knowledge, which are critically acquired through effortful observation of ancestors of the present generation and passed on from generation to generation within this community. The approach that successive governmental and non-governmental organizations have been implementing is food relief for the drought-affected population. Nowadays, those inhabitants have been expecting emergency food aid from the outside world in every severe drought that has been occurred in the region (Shikuku 2017).

Nearly all studies on effects of personal experience on self-protective behavior regarding natural hazards have shown that preparedness had been increasing with the severity of past damage (Weinstein 1989). Our study started by understanding and identifying Afar society's perception on what climate change is. Then, those identified risks have to be defended by proper adaptation strategies. In our study, the major challenging experience that almost all inhabitants of Afar have experienced, shared, and blamed for was that the damage caused to their resource by recurrent drought. Most elders among Afar pastoralists bear past drought events and its severity in their mind. Therefore, local story tellers mostly use the most sever and devastating droughts in history as time boundaries such as that of Keda Amena, which is used by Afar pastoralists to refer to the drought of 1984.

For our study, it seems reasonable to assume that risk experience appraisal plays an essential role in motivating people to take adaptive action against climate change. Even if the drought-affected community members have gotten an emergency food aid from the outside world, it was too slow to reach them before immense damage was caused to the affected society. Thus, the best solution to rely on has to be those local coping strategies adopted by the local herders. The extent of impacts depends largely on communities' awareness and the level of local adaptation strategies in response to climate change (Fosu-Mensah et al. 2012). The role played by the indigenous ecological knowledge in helping the local pastoral communities to minimize the damages caused by frequent droughts and local indicators used by the pastoral society in evaluating conditions of the components of their environment should be prioritized. Government's effort in addressing the information gap that local communities have experienced about what has been happening globally should focus on engaging them to participate in a way to become part of the solution in the process of mitigating climate change. Pastoralists' understanding about climate change should be assessed to talk about the best solutions that can help them to resolve it. Our study is based on the Protection Motivation Theory (PMT) developed by Rogers (1983) and also adopted by Grothmann and Patt (2005), which is a sociocognitive model of private proactive adaptation to climate change. Such theoretical framework helps to see differences in the perceptions of respondents among different areas, societies, and communities, as well as at an individual level. The objective of an adaptive capacity is directly related to the management of resource such as time, money, knowledge, entitlement, and social and institutional support. Perception is the key process throughout the PMT model to reach up on adaptive intention. However, the basic two components of PMT adaptation model is climate change risk appraisal and adaptation appraisal, which are also composed of perceived probability and perceived severity. Perception adaptation efficacy perceives self-efficacy and adaptation costs that help to reach up on avoidant maladaptation (i.e., fatalism, denial, and wishful thinking) and adaptation intention. According to this theory, adaptation appraisal comes after the risk perception process and only starts if a special or threshold of threat appraisal is exceeded. Thus, a minimum level of threat or concern must exist before people start contemplating the benefits of possible actions and ruminate their competence to actually perform them (Schwarzer 1992). Possibly, addictiveness is a question of "best fit" to an objective situation in which a person finds him- or herself. Therefore, an avoidant reaction, such as denial of the risk of drought, could also be seen as an adaptive coping strategy for a community that has been frequently hit by drought, who objectively has very little means of preventing drought. In such a case, denial would be an adaptive response to protect individuals' or communities' psychological wellbeing before drought occurs, although this response would not be an 
adaptive one in the sense of preventing the damage caused, if drought actually occurs.

This model is currently accepted as one of the four major theories within the domain of psychological research on health issues. However, it is also broadly applicable in the area of natural and technological hazards identification (Mulilis and Lippa 1990). Little studies have been done using PMT. According to Grothmann and Patt (2005) the use of this theoretical framework enables researchers to come up with empirical evidences that clearly inform the science of decision-making, at various levels into the research for climate change risk appraisal and adaptation strategies.

\section{Methods}

\section{Study area and sampling}

The study was conducted in two districts of zone III of Afar Regional State, which is included in the Middle Awash basin, North-Eastern part of Ethiopia. Middle Awash basin is located at an altitude ranging from 500 to $600 \mathrm{~m}$ between $9^{\circ} 30^{\prime}$ and $10^{\circ} 20^{\prime} \mathrm{N}$ and $40^{\circ} 30^{\prime}$ and $40^{\circ} 50^{\prime} \mathrm{E}$. The two districts are generally characterized by high temperature, which ranges from $28{ }^{\circ} \mathrm{C}$ to $42{ }^{\circ} \mathrm{C}$, with an average annual temperature of $35^{\circ} \mathrm{C}$, and receive an average annual rainfall of $320 \mathrm{~mm}$ (Farm Africa 2009). The study areas are largely covered by bushes, shrubs, and predominantly swampy vegetation. The indigenous vegetation is now replaced by Prosopsi Juliflora tree. Areas away from the Awash River have scattered clumps of short and thorny Vachelia and Senegalia trees with sparse grasses.

In the survey, a multi-stage sample design was adopted. Firstly, we selected purposely two adjacent districts namely Amibara and Gewane for this particular study. The two districts are similar in terms of ethnicity, production system, and agro-ecology. They are predominantly inhabited by Afar pastoralists and characterized by pastoral production system. Minor differences between the two districts refer to the degree and frequency of implementation of development interventions. The terms intervened and non-intervened were used in this study to represent Amibara and Gewane districts, respectively. The intervened district (i.e., Amibara) and respondents drawn from PAs of Amibara district were used as an experimental group, while the non-intervened district (i.e., Gewane) and respondents from this district were used as a control group. On the one hand, the term "intervened" was particularly used to represent relatively large and frequent interventions by government and non-governmental organizations (NGO) that were aimed to expand private farming and implement government imposed settlement programs. On the other hand, "non-intervened" used to represent PAs that were relatively free from implementation of large and frequent farming both at private and state levels, as well as free from implementation of settlement program with non-regular NGO intervention. This study gives special consideration for interventions related to private- and state-based large scale commercial agriculture, policy-oriented settlement programs, and operational NGO's programs. The second stage was purpose-oriented selection of PAs from each district. Accordingly, Adbaro and Beida PAs were selected from Gewane, while Alaysumela and Eeble were the two PAs selected from Amibara district. Our approach in selecting these PAs was to ensure a meaningful representation of the study areas. In due course, random selection of households (HHs) from each sample PAs was made based on pastoralists list from community leaders as facilitators.

Household interview was conducted following the complete list of pastoral $\mathrm{HHs}$ as provided by community leaders in each of the selected PAs. Participants in the one-to-one household interview were pastoral elders whose ages were above 50 years old. Overall, a total of 100 pastoral elders were interviewed from the four PAs (25 elders per PA) in the two study districts.

\section{Data collection and analysis}

Focus group discussions (FGDs) and key informants' interviews (KIIs) were conducted using a participatory rural appraisal (PRA) tools (Mercado, 2006). The interview developed were an open-ended, discovery-oriented, and semi-structured questionnaire, which was conducted to understand pastoralists' insight, feeling, thought, and opinion about the impact of external development interventions and their perception towards climate change settings and the emerging mitigation and adaptation strategies among members of the community. For the semi-structured questionnaire interview, a household was taken as a unit of analysis. Randomly selected pastoral HHs from the four PAs was used to gather information related to the socio-economic and rangeland resource management.

Those selected PAs had proportionally equal number of rural HHs. The questionnaire was consisted of both closeand open-ended questions. The semi-structured questionnaire was translated into the local language "Afaraf" and pre-tested, and necessary adjustments were made accordingly prior to the actual $\mathrm{HH}$ interview. While doing the survey, objectives of the study were explained and discussed with informants, community leaders, and participants in order to ensure their cooperation.

A total of four trained enumerators (one per PA) were hired, and questionnaires were filled under close supervision that allowed replacement of sampled HHs in times of involuntary response or unavailability. Besides the first author, two development agents (i.e., one for each district) were hired to make a close supervision on the data collection process at the household level. The process 
of data collection in the study areas took place between 12 February and 21 March 2015.

The trends in temperature and precipitation were analyzed by dividing time of the year into four Afar seasons namely the long rainy season (Kerma) from July to September, cold dry seasons (Gillal) from October to January, short rainy season (Sugum) between March and April, and the dry season (Hagay) from May to June. The Afar rangeland has two major known rainy seasons namely Kerma and Sugum. The severity of drought and shortage of feed and water in pastoral areas such as the Afar rangeland depend significantly up on the amount of rain the area received. The present study analyzes the coping strategies that are based on the level of precipitation the study area has received. Mobility can be taken as a unique adaptation and coping mechanism by pastoralists like the Afar in North-Eastern and Borana in southern parts of Ethiopia. Based on the local situation, our study mainly focused on understanding of the coping strategies that linked with mobility to overcome the familiarity of rain during the two rainy seasons.

Pastoral coping strategies due to the failures of the short and long rainy seasons were assessed and seen in relation to the socio-economic characteristics of HHs. In the present study, mobility was used as a common interest of all pastoral HHs, which is confirmed from FGDs with members of the pastoral society in the study districts. Accordingly, mobility was collaborated with other coping choices and tried to assess coping strategies at different rainy seasons.

The filled-in questionnaires were first checked and coded. After a careful review, the data were entered into a computer and analyzed using SPSS software programs. Statistics like percentages, mean, sum, range, standard deviation, and statistical tools like cross-tabulation were also employed during data analysis.

Logit model was used to analyze the coping strategies of pastoral HHs that have significant relationship with different pastoral households' characteristics (Tables 1, 2, and 3). It was employed due to the nature of the decision variable: whether farmers perceived climate change and have adapted or otherwise. For such a dichotomous outcome, the logit model is the most appropriate analysis tool. The logit model considers the relationship between a binary dependent variable and a set of independent variables, whether binary or continuous. The logit model for $k$ independent variables $\left(\chi_{1}, \chi_{2}, \chi_{3}, \ldots, \chi_{k}\right)$ is given by

$$
\operatorname{logit} P(x)=x+\sum_{i=1}^{k} \beta 1 x \text { i. }
$$

$\operatorname{Exp}\left(\beta_{\mathrm{i}}\right)$ indicates the odds ratio (i.e., the ratio of favorable to unfavorable outcomes) for a person having characteristics $i$ versus not having $i$, while $\beta$ is the regression coefficient and $X$ is a constant.

\section{Results \\ Pastoralists' knowledge of rangeland condition rating}

The relationship between different range condition indicators and pastoralists' perceptions towards the different indicators of climate change is presented in Fig. 1. More than $50 \%$ of the respondents from the two study districts agreed that the number of livestock owned by a household was the best indicator of rangeland condition throughout the year. Furthermore, pastoralists also mentioned that they used plant productivity, pasture yield, plant height, and plant diversity as indicators of rangeland condition rating (Fig. 1). Pastoralists' observations showed that there were high inter-seasonal fluctuations in terms of pasture yield, plant height, and plant diversity. Especially, more than $90 \%$ of the respondents asserted that in late dry season (DS), the importance of livestock number owned by a household as indicator of rangeland condition become more critical than other seasons. Respondents believed that the number of livestock gradually decreased with the advancement of the dry season and scarcity of forage. Respondents further felt that due to the impact of feed scarcity, the body conditions of livestock were emaciated and eventually resulted in reduced milk production and the quality of animals for sale where pastoral households become more vulnerable to food insecurity and other risks. About $50 \%$ of the respondents mentioned that they considered the status of plants' productivity as second preference as indicator of rangeland condition. Respondents' perceptions in terms of other indicators of rangeland condition like plant species diversity, plant height, and plant yield (biomass) were not as agreeable as the two indicators mentioned above.

\section{Actual trends in temperature and rainfall}

Figure $2 \mathrm{a}, \mathrm{b}$ presents the actual temperature and precipitation from the metrological record between 1971 and 2012 (Source: Werer Agricultural Research Center 2013). The metrological data records showed that there was no significant decline in terms of precipitation in all Afar seasons, except a slight decrease during the cold dry seasons between 1997 and 2012. Other seasons showed the erratic nature of precipitation with high fluctuations instead of showing a permanent change, i.e., either an increasing or a decreasing trend in precipitation in all those years. However, the recorded temperature data showed that there was an increase in temperature in all Afar seasons. Especially, the dry (Hagay) and short rainy (Sugum) seasons showed a uniform increase in temperature as compared to other seasons. The change was seen during the dry season since 1983 , which was $28.75^{\circ} \mathrm{C}$, and further increased to an average temperature of $32^{\circ} \mathrm{C}$ over the past 


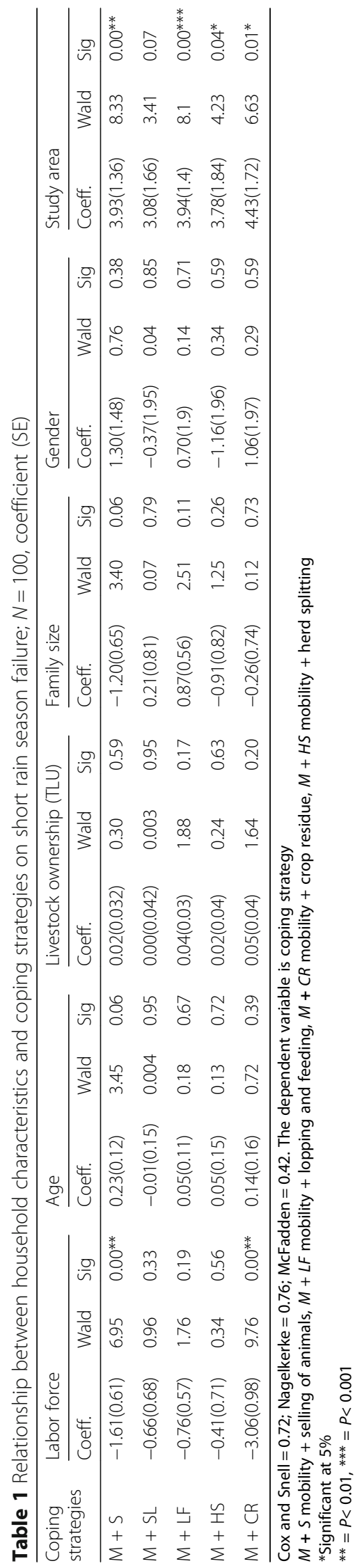




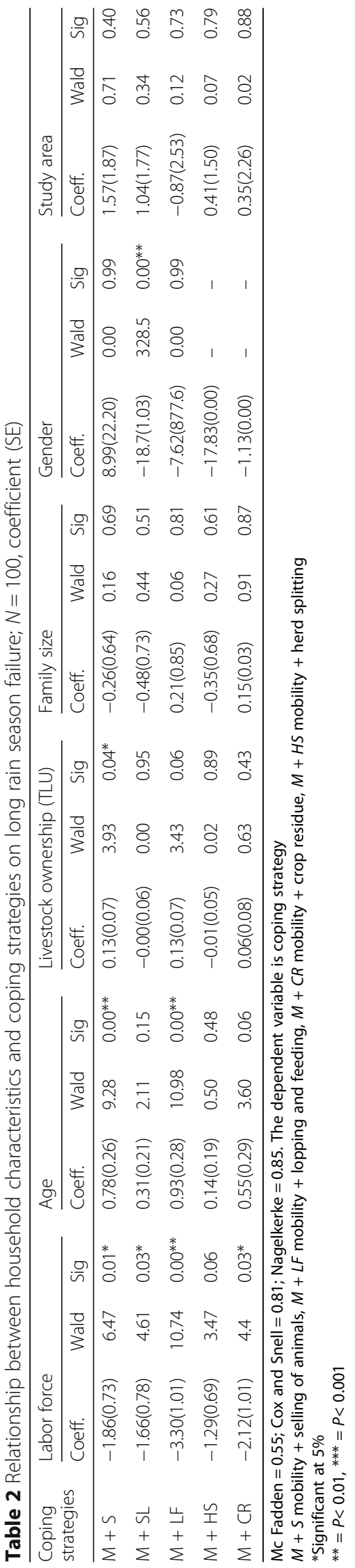


Table 3 Summary statistics of survey data, in Afar region of Ethiopia

\begin{tabular}{llll}
\hline Variables & Study area & & Total $(N=100)$ \\
\cline { 2 - 3 } & Amibara $(N=50)$ & Gewane $(N=50)$ & $39.45(11.68)$ \\
\hline Age & $40.14(11.30)^{a}$ & $38.78(12.14)$ & $7.98(2.13)$ \\
Family size & $7.98(2.22)$ & $7.98(2.06)$ & $0.07(0.26)$ \\
Gender & $0.06(0.24)$ & $0.08(0.27)$ & $4.82(2.59)$ \\
Labor force & $5.02(2.25)$ & $4.62(2.90)$ & $0.26(0.44)$ \\
Education level & $0.24(0.43)$ & $0.30(0.45)$ & $26.94(21.89)$ \\
No. of livestock owned & $13.46(9.2)$ & $40.42(22.63)$ & \\
\hline
\end{tabular}

${ }^{\mathrm{a} N u m b e r}$ in parenthesis is standard deviation

decade. The increase in temperature during the SRS showed a similar trend as that of the dry season. A slight difference between the two seasons was observed in 1983 and 1988 when the deviation began. However, the other seasons showed some variation in comparison to the above two seasons.

\section{Perceptions of pastoralists towards climate change}

Pastoralists' opinion towards climate change indicators in the study area are presented in Fig. 3. More than $80 \%$ of the respondents perceived that there was a decrease in the length and amount of precipitation in SRS and LRS in the last few decades. Above $90 \%$ of the pastoral
HHs from the study districts had recognized the change in full-year precipitation.

Almost all respondents agreed that the DS temperature increased, whereas $75 \%$ of our respondents agreed that the SRS temperature increased in the last few decades. There existed a slight variation among respondents perception in terms of change in temperature among the different seasons in Afar. To some extent, respondents agreed that temperature during the cold dry season (CDS) showed an increase in the past few decades. However, no significance difference was observed between the two study districts as a result of difference in the degree and frequency of development interventions.

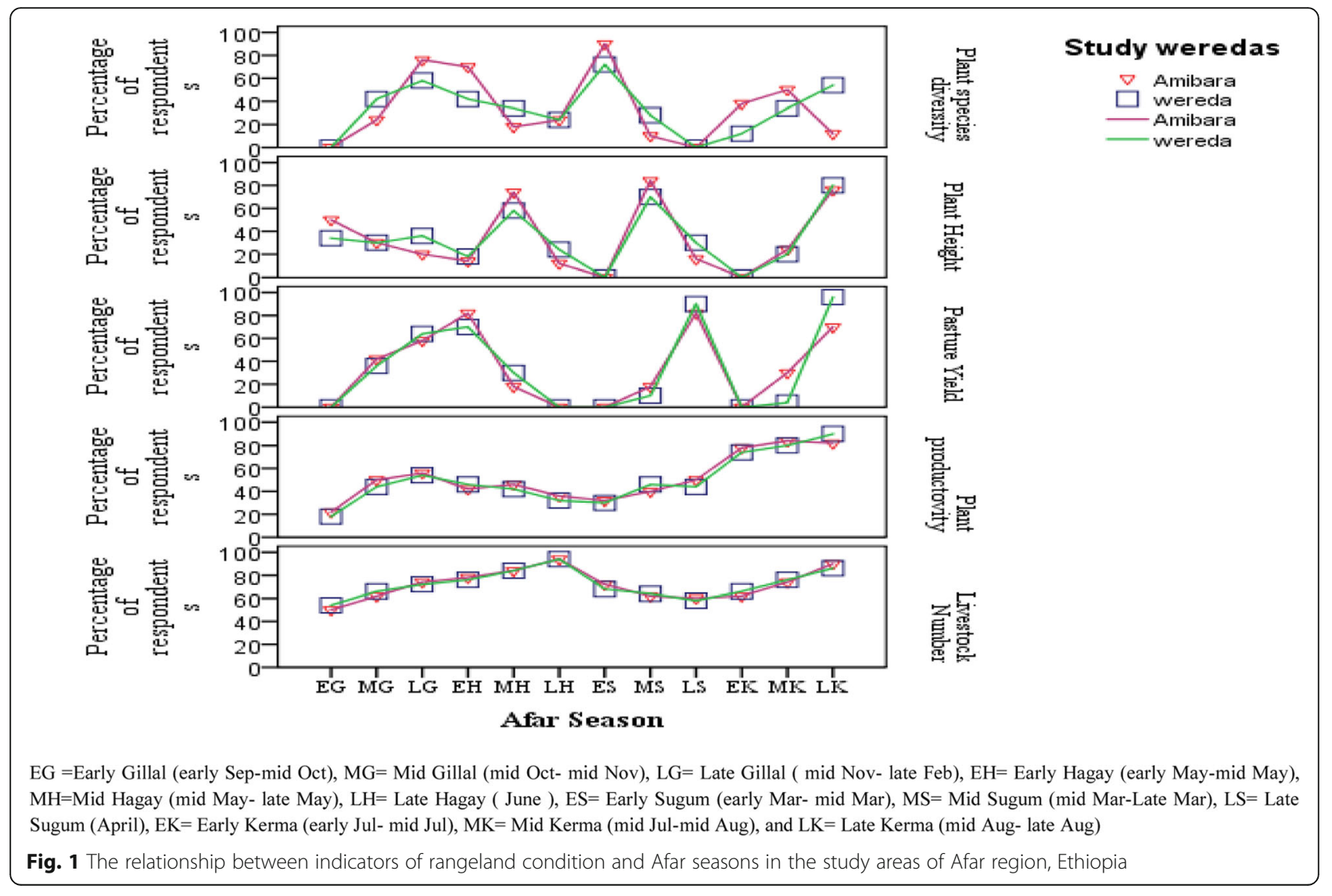




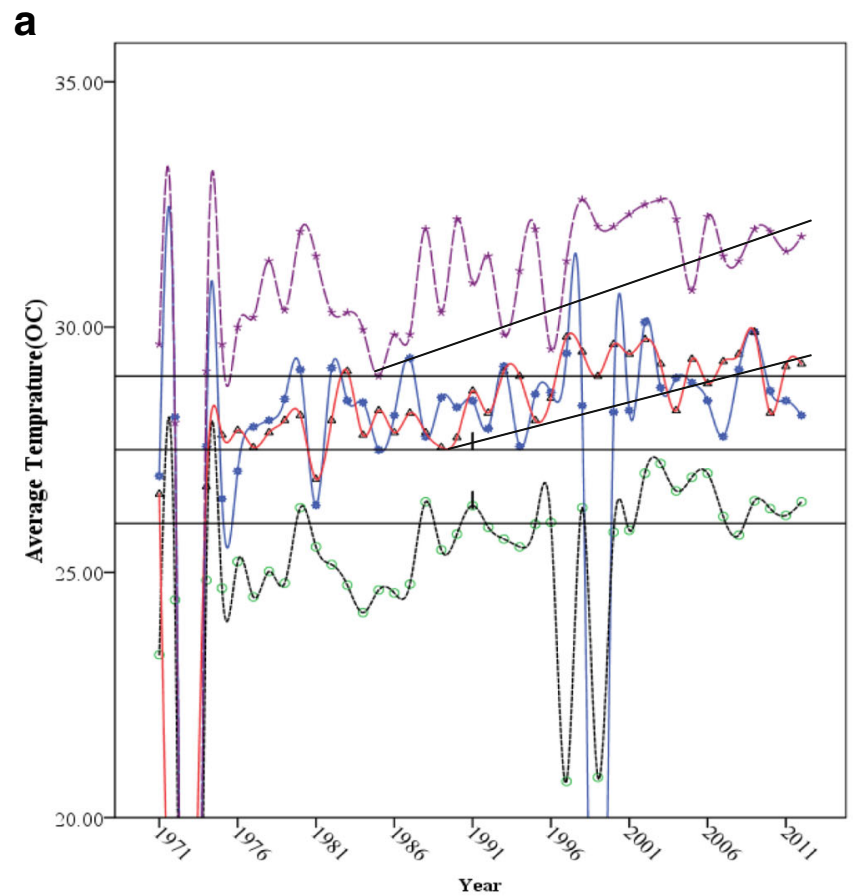

Differnt Afar seasons

站 Kerma

Gillal

$\triangle$ Sugum

$\star$ Hagay

- Kerma

- Sugum

-- Hagay

b

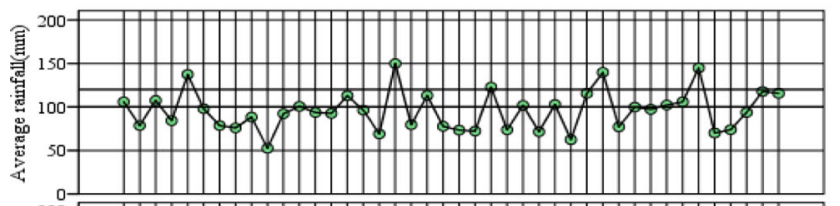

Key

O Rainfall
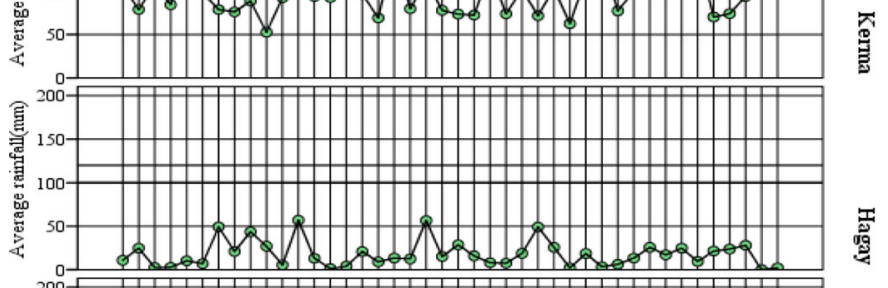

要
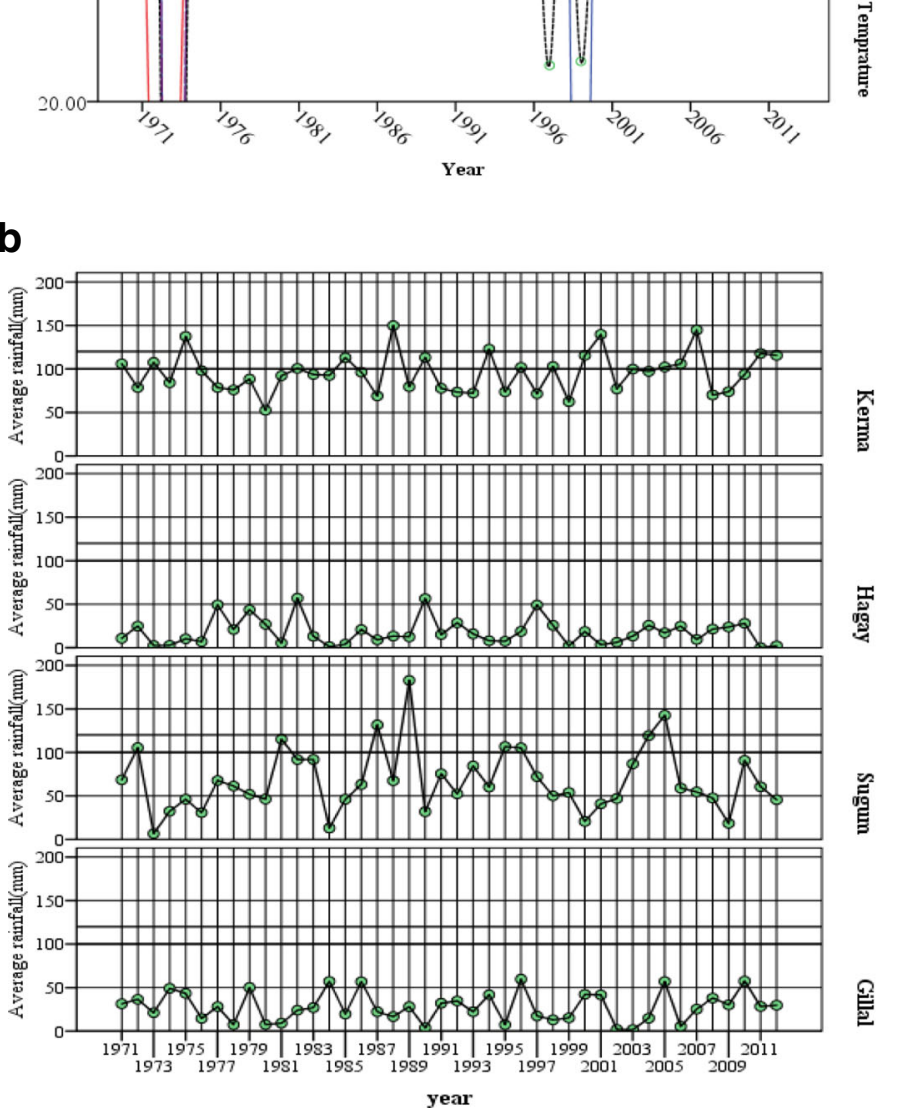

番

离

异

Fig. 2 a Actual temperature metrological record from 1971 to 2012. b Actual rainfall metrological record from 1971 to 2012 (Source: Werer Agricultural Research Center

Herders perceptions versus actual metrological records of climate change

The recorded metrological data did not show any significant decline in precipitation for the last four decades (i.e., from 1971 to 2011) as opposed to the response of pastoralists where the majority $(80 \%)$ perceived that there was a decline in precipitation during the different seasons in the study areas. The existing temperature records by the metrological station showed minor variability across years. Over the last four decades, there was 


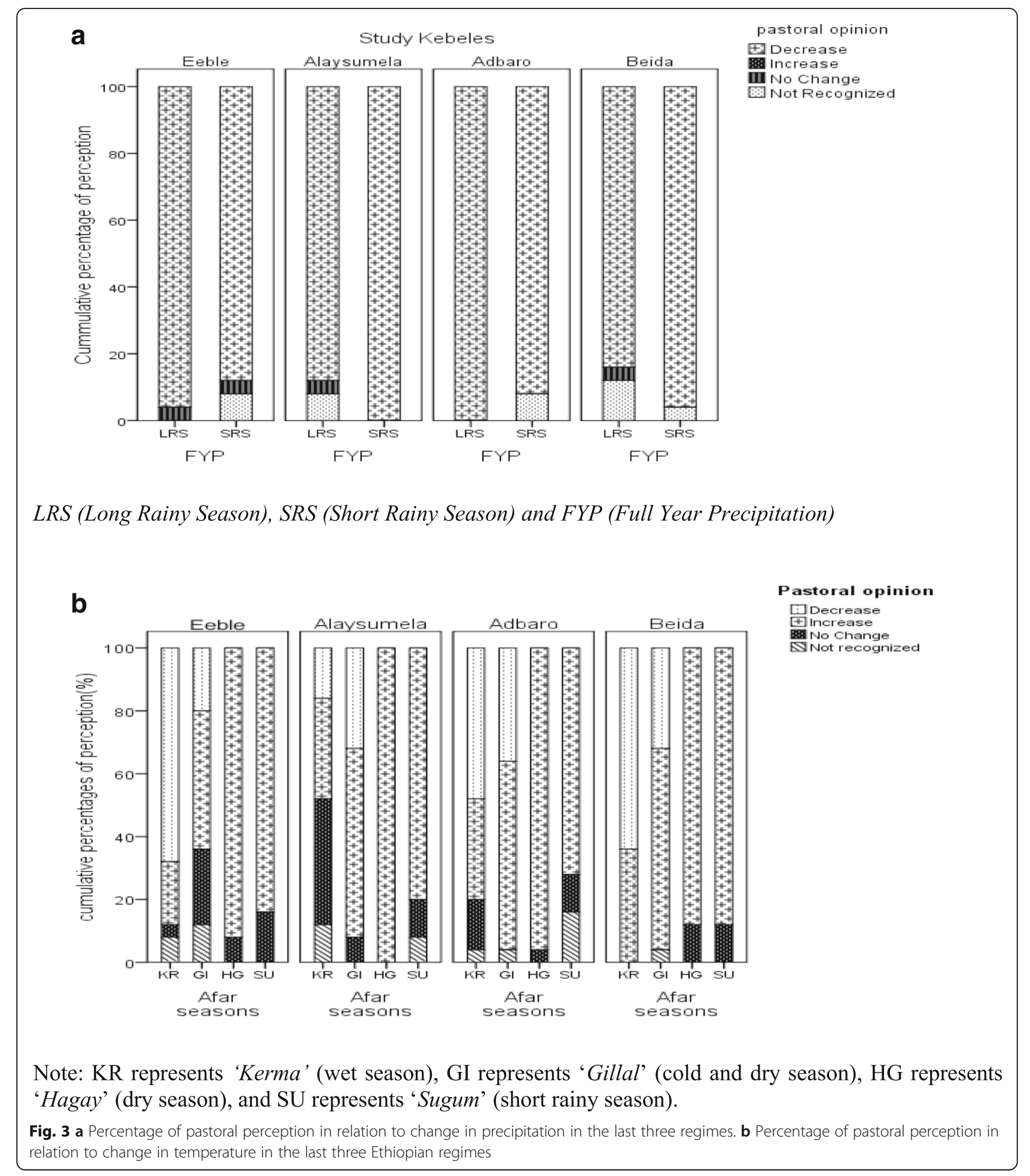

a significant increase in temperature during the different seasons of Afar. More than 70\% of our respondents perceived that there was an increase in temperature during the SRS and DS. However, there was an attitude differences among respondents as observed in the case of LRS and CDS.

\section{Coping strategies on different Afar rainy seasons Coping strategies towards failure of the short rainy season}

The estimated coefficient of most coping strategies towards failure of the SRS showed a negative relationship with the number of labor force found at a 
household level. However, significance difference was observed between the different rainy seasons in terms of coping strategies that had used for the failure of rainfall. Mobility + selling showed a significant relationship with an estimated coefficient of $-1.61(P=$ 0.008) (Table 1). An isolated one unit increase in labor force showed about $16.1 \%$ decrease in the choice of livestock selling as a coping strategy. Differences in the study area in terms of adaptation showed a significant relationship in all coping strategies except mobility + slaughtering with an estimated coefficient of 3.93 $(P=0.00)$. This showed that the non-intervened pastoral HHs had about $39.3 \%$ more choices to use mobility + looping and feeding than the intervened pastoral HHs (Table 1). In addition, other coping strategies also showed a significant relationship with the type of the study area. The estimated coefficient of the study area for mobility + herd splitting is $3.78(P=0.04)$, which showed non-intervened pastorals $\mathrm{HHs}$ with $37.8 \%$ more preference to use mobility + herd splitting than the intervened pastoral HHs (Table 1). Similarly, the estimated coefficient of $4.43(P=0.01)$ showed that the non-intervened pastoral HHS had about $44.3 \%$ more preference than the intervened pastoral HHs (Table 1).

\section{Communities' coping strategies towards failure of long rainy season}

The estimated coefficient of mobility and selling for the choice of labor force is $-1.86(P=0.00)$, which displayed that a one-unit increase in HH's labor resulted in a decrease in the choice of mobility and selling by $18.6 \%$ as coping strategy (Table 2). A similar relationship was also observed in terms of mobility + crop residue as coping strategy by pastoralists. The estimated coefficient of $-2.12(P=0.03)$ showed that a one-unit increase in labor force resulted in $21.2 \%$ decline in the choice of mobility and crop residue. Other coping strategies such as mobility + looping and feeding, and mobility + slaughtering had an estimated coefficient of -3.30 and -1.66 , respectively (Table 2). The estimated coefficient for age was $0.78(P=0.00)$, which showed that a 1-year additional difference in the age of respondents resulted in $7.8 \%$ increase in pastoralists' preference to choose selling of their livestock (Table 2). Similarly, an estimated coefficient of $0.93(P=0.000)$ was observed for age, which showed $9.3 \%$ increase in terms of pastoralists' preference to use looping + feeding to cope up with the failure of rainfall. Pastoral gender difference had an estimated coefficient of $-1.87(P=0.00)$, which displayed that a male pastoral HH's preference of $18.7 \%$ is fewer than that of female pastoral HH's preference in terms of slaughtering their stock at the times of rain failure (Table 2).

\section{Discussion}

The present findings in terms of rangeland condition assessment as perceived by Afar pastoralists in Ethiopia is similar to the results of others (Holechek et al. 2001; Angassa and Beyene 2003), who indicated that reduction in plant productivity and livestock number are the main indicators of rangeland deterioration attributed to the impact of climate change. It is important to note that pastoralists' perceptions are all about the knowledge that is available in connection with their local environment, which is critical in decision-making based on those verifiable truths. Increasing land use changes, as human demand for food and natural resources rise in dry land ecosystems, eventually contributes to climate change (Grover et al. 2011). These changes have been indicated and tackled using pastoral communities' knowledge towards seasonal rainfall and temperature changes. The increase in DS's temperature that has been perceived by most respondents of the study area is in line with PFE, IIRR, and DF (2010) and NMA (2007), which have reported that temperature in the lowland of Ethiopia is generally predicted to increase by more than $0.1^{\circ} \mathrm{C}$ in the next century. In addition, scientists expect that the average global surface temperature could rise by 1 to $4.5{ }^{\circ} \mathrm{F}$ $\left(0.7-2.5^{\circ} \mathrm{C}\right)$ in the next 50 years and by 2.2 to $10{ }^{\circ} \mathrm{F}$ $\left(1.4-5.8{ }^{\circ} \mathrm{C}\right)$ in the next century with a significant variation in regional temperature (FAO 2008).

The Afar pastoralists of Ethiopia are aware of the change in climate, and they have a clear opinion about the changes in precipitation and temperature during the last few decades. However, the existing metrological records are in contrast with the opinion of pastoralists in terms of precipitation in the LRS and CDS of the study area. The results of the current study are in agreement with a previous study by Li et al. (2014), who suggested a decline in precipitation over years. However, no significant change has detected in terms of the existing precipitation records. The importance of focusing on those local indicators as early warning systems is to minimize the negative impact of climate change on livestock population dynamics. Others (Angassa and Oba 2007; Angassa et al. 2012) have shown that inter-annual rainfall variability followed by extreme forage fluctuations can cause greater die-off of the livestock population. Although Afar pastoralists were frequently affected by the impact of drought, those coping strategies adopted by the local communities are key in terms of communities' responses to ecological crisis that occurred in the study areas. Similarly, in the neighboring country in Sudan, pastoralists use indicators like rainfall pattern that has a significant role in the process of minimizing the damage caused by climate change (Sulieman and Ahmed 2013).

Pastoralists are victims in situations where drought and feed shortage cause die-offs of a great number of livestock 
that are the source of their income and food and taken as prestige for the Afar society. Hence, strengthening the strategies for mitigation and adaptive capacity of the most vulnerable and disadvantaged groups of the society is a priority and key decision. Strategies such as opportunistic herd management and flexibility for utilizing available rangeland resources in space and time have been considered as environmentally sound for minimizing risks of droughts in arid lands of East Africa (Ellis and Swift 1988; Angassa and Oba 2007; Angassa et al. 2012). Mobility is number one preference of pastoralists in response to seasonal changes in rainfall and fluctuation of forage resources in both study districts, which is believed to cause huge damage on livestock resources and pastoralists' livelihood if not supported by mobility. Similarly, other studies (Angassa and Oba 2007; Abate et al. 2010; Megersa 2013) have also reported herd mobility as the best strategies in response to the effects of recurrent droughts and scarcity of grazing and water resources (McCabe 2004) in Southern and Eastern parts of Ethiopia. In the current study, the perceptions of Afar pastoralists have shown that mobility is their first choice in terms of adaptation to the impact of climate change. The situation is confirmed by FGDs held in all the selected PAs and from almost all Key Informants (KIs) in the study districts.

In the ever-continuing quest for finding a suitable and effective remedy against failure of rainfall, researchers have analyzed coping strategies that have been used by the pastoral community for long periods. The current findings have shown that respondents' labor forces have a significant relationship with the coping strategies such as mobility + selling and mobility + use of crop residue due to the failure of rainfall in SRS. Respondents' labor forces are also significant with all the listed coping strategies except mobility + herd splitting as a result of the failure of rain in the LRS. The probable explanation could be due to herders' demands for more labor force to manage the different species of livestock that need higher number of laborers. If the labor demand is not fulfilled, pastoralists may choose to sell their livestock although they do not want to lose their herd size without value addition. The significant relationship that was observed between mobility + selling and differences in terms of external influence in the study areas may contribute to the variability in terms of livestock holdings between the two districts. This reflects variation between the two districts in terms of communities' preferences in selling their livestock before large proportion of animals are lost as a result of drought that might allow the remaining livestock to survive on the scarce feed resources during shortage of rain. The results of the current finding agree with the activities of the Prime project (2015) in Jigjiga and Borana that is designed to support resilience among pastoral communities in Ethiopia. Furthermore, the exists a significant relationship between there study areas and mobility + labor force, which may be attributed to the risk aversion nature of the pastoral households and lack of trust in keeping livestock for the whole dry seasons where they might also be busy in looking for other shortcut options to minimize risks. Our results are in line with the findings of Mwenda and Laswai (2013) in Magu and Ilemela districts, Lake Victoria basin, suggesting that herd size and age of the $\mathrm{HH}$ head has a significance relationship with the different coping strategies adopted by pastoralists. Consequently, the results of the present study have revealed that Afar pastoralists have a detailed knowledge and experience in dealing with the different risks caused by climatic variability and change. However, various factors, such as their marginalization in decision making concerning their resource use, lack of education, and access to basic services might restrict their capacities to adapt to climate change.

\section{Conclusions}

Afar pastoralists have long years of experience in terms of responding to the impacts of climate change through analysis and evaluation of the local situations with regard to issues central to their livelihood. However, their efforts were largely overlooked by inappropriate land use policies and development interventions. Pastoralists' observations suggest that livestock number and plant productivity were the best indicators for rating rangeland condition. The findings of this study confirmed that pastoralists' perceptions are well-matched with the existing meteorological analysis in terms of the increased trend of temperature during the two Afar rainy seasons. Pastoralists' perceptions of downward trend in precipitation were not supported by the existing meteorological analysis. Generally, the short rainy season was the best indicator in terms of drought occurrence in the study districts with a clear indication of recurrent droughts in history (1972/73; 1984/85; 1991; 2000).

These findings have significant implications in terms of informing pastoral development and policy directions in future development strategies that help to build on pastoralists' experiences and knowledge with regard to local specific community development rather than constraining them. More importantly, pastoralists' lifetime experiences in terms of environmental indicators could be more helpful in early warning system for strengthening drought resilience and enhancing sustainable development. We suggest a need for appropriate interventions ensuring management of rangeland and water availability so as to improve livestock productivity. Finally, we recommend further research to look into the psychosocial reflex of herders to shock which enable them in the face of climate shock that require quick adaptation mechanism. 


\section{Acknowledgements}

The authors acknowledge those pastoral communities and officials in the study areas for their cooperation and assistance during fieldwork. We also thank the Ethiopian Ministry of Agriculture for the financial assistance to conduct the research work. We are grateful for the valuable comments from reviewers for the improvement of the quality of our manuscript.

\section{Authors' contributions}

MT conducted the field research, analyzed the data, and drafted the manuscript. AAn and AAb designed the research, interpreted the results, and were involved in the manuscript writing. All authors revised the manuscript and read and approved the final version.

\section{Competing interests}

The authors declare that they have no competing interests.

\section{Publisher's Note}

Springer Nature remains neutral with regard to jurisdictional claims in published maps and institutional affiliations.

\section{Author details}

'College of Agriculture and Natural Resources, Wolkite University, Gubrei, Ethiopia. ${ }^{2}$ Botswana University of Agriculture and Natural Resources, Gaborone, Botswana. ${ }^{3}$ School of Animal and Range Sciences, Hawassa University, Hawassa, Ethiopia.

Received: 13 April 2017 Accepted: 30 June 2017

Published online: 10 August 2017

\section{References}

Abate T, Ebro A, Nigatu L (2010) Traditional rangeland resource utilization practices and pastoralists' perceptions on land degradation in south-east Ethiopia. Tropical Grasslands 44:202-212

Angassa A, Beyene F (2003) Current range condition in southern Ethiopia in relation to traditional management strategies: the perceptions of Borana pastoralists. Tropical Grasslands 37:53-59

Angassa A, Oba G (2007) Relating long term rainfall variability to cattle population dynamics in communal rangelands and a government ranch in southern Ethiopia. Agric Syst 94:715-725

Angassa A, Oba G, Stenseth NC (2012) Community-based knowledge of indigenous vegetation in arid African landscapes. J Sustain Dev 8:70-85

Carver CS (1998) Resilience and Thriving: Issues, Models and Linkages. J Soc issues 54(2):245-266.

Ellis JE, Swift DM (1988) Stability of African pastoral ecosysytems, alternate paradigms and implication for development. J Range Manag 41:450-459

FAO (2008) Proceedings International conference on livestock and global climate change. Hammamet, Tunisia, BSAS, INRA, ICARDA, EAAP, OEP, IRESA, CIRAD, ILRI, ESF, Scottish Government, RIU International Conference-for further information www.bsas.org.uk

Farm Africa (2009) A livelihood baseline survey in Amibara and Gewane Districts of Afar region. The Afar Prosopis Management Project document. Final report 1: p. 119

Fosu-Mensah BY, Vlek PL, MacCarthy D (2012) Farmers' perception and adaptation to climate change: a case study of Sekyedumase district in Ghana. Environ Dev Sustain 14:495-505

Grothmann T, Patt A (2005) Adaptive capacity and human cognition: the process of individual adaptation to climate change. Glob Environ Chang 15:199-213

Grover S, Livesely J, Huntley LB, Jamali H, Beringer J (2011) Land use change and impact on greenhouse gas exchange in Northern Australian Savanna soils. Biogeosciences 9:423-437

Helland J (2006). Land tenure in pastoral areas of Ethiopia. ILRI, Addis Ababa, Ethiopia.

Helland J (2015) Afar resilience study for Feinstein International Center (Tufts University) and Afar Region Disaster Prevention, Preparedness and Food Security Coordination Office, Afar Regional State, Ethiopia. CMI working paper, WP 2015:06. CHR. MICHELSEN INSTITUTE.

Holechek JL, Pieper RD, Herbel CH (2001) Range management principles and practices, 4th edn. Prentice Hall, Upper Saddle River, NJ

Hou XY, Han Y, Li FY (2012) The perception and adaptation of herdsmen to climate change and climate variability in the desert steppe region of northern China. Rangeland J 34:349-357
Li X, Wang Z, Hou X, Liu Z, Sarula YY, Ding Y, Hu J (2014) Herders perception of climate change does not always fit with actual climate change. Rangeland J 36:557-564

McCabe J (2004) Cattle bring us to our enemies: Turkana politics, and raiding in a disequilibrium system. The University of Michigan press, Ann Arbor

Megersa B (2013) Climate change, cattle herd vulnerability and food insecurity: adaptation through livestock diversification in the Borana pastoral system of Ethiopia. PhD Thesis. Faculty of Agricultural Sciences at the University of Hohenheim, Stuttgart-Hohenheim, p 169

Mercado DZ (2006) A Manual on Processing and Reporting of Participatory Rural Appraisal (PRA) Data for Natural Resource management. GTZ Pacific German Regional Forestry Project. pp 51-67

Mohammed Y (2010) Is it a silent travel to death? Case of the Subaltran Children of Lucy. Uppsala, Sweden

Mulilis JP, Lippa R (1990) Behavioural change in earthquake preparedness due to negative threat appeals: a test of protection motivation theory. J Appl Soc Psychol 20:619-638

Mwenda E, Laswai E (2013) Economic evaluation of agro-pastoral coping strategies to effects of climate change and variability in Magu and Ilemela districts, Lake Victoria Basin. Business Consultancy, Kizpat Resources Co. Ltd, P.O. Box 7584, Mwanza - Tanzania

National Metrological Agency (NMA) (2007) National adaptation programme action of Ethiopia., p 150

Pastoral Forum Ethiopia (PFE), International Institute for Rural Re-construction (IIRR) (2010) Land tenure, administration and use in pastoral areas of Ethiopia workshop proceeding. March 2009, Addis Ababa, Ethiopia

Rogers RW (1983) Cognitive and physiological processes in fear appeals and attitude change: a revised theory of protection motivation. In: Cacioppo BL, Petty LL (eds) Social psychophysiology: a sourcebook. Guilford, London, UK, pp 153-176

Schwarzer R (1992) Self-efficacy in the adoption and maintenance of health behaviours: theoretical approaches and a new model. In: Schwarzer R (ed) Self-efficacy: thought control of action. Hemisphere, Washington, DC, pp $217-243$

SFDRR (2015) Sendai framework for disaster risk reduction 2015-2030. At the Third UN World Conference in Sendai, Japan, on March 18, 2015

Shikuku KM, Winowiecki L, Twyman J, Eitzinger A, Perez JG, Mwongera C, Läderach P (2017) Smallholder farmers' attitudes and determinants of adaptation to climate risks in East Africa. Clim Risk Manag 16:234-245.

Sulieman HM, Ahmed AGM (2013) Monitoring changes in pastoral resources in eastern Sudan: A synthesis of remote sensing and local knowledge. Pastoralism: Research, Policy and Practice 2013, 3:22 http://www. pastoralismjournal.com/content/3/1/22.

Tambo JA, Abdoulaye T (2013) Smallholder farmers' perceptions of and adaptations to climate change in the Nigerian savanna. Reg Environ Chang 13:375-388

Weinstein ND (1989) Effects of personal experience on self-protective behaviour. Psychol Bull 105:31-50

Werer Agricultural Research Center (2013). Werer Agricultural Research Center Meteorological Station, Ethiopia, Werer, Afar Region Zone III.

\section{Submit your manuscript to a SpringerOpen ${ }^{\circ}$ journal and benefit from:}

- Convenient online submission

- Rigorous peer review

- Open access: articles freely available online

- High visibility within the field

Retaining the copyright to your article

Submit your next manuscript at $\boldsymbol{\nabla}$ springeropen.com 